\title{
ANALYSIS OF THE INFLUENCE OF LEAN CONSTRUCTION AND LEED CERTIFICATION ON THE QUALITY OF CONSTRUCTION SITES
}

\author{
Thaís Cunha ${ }^{1}$ and Mariana M. X. Lima ${ }^{2}$
}

\begin{abstract}
Adequate planning of construction sites guarantees better efficiency, productivity, quality on the development of all work activities, optimization of the physical available space, workers' safety and motivation in performing their duties. The objective of this paper is to verify the influence of Lean Construction and LEED Certification on the quality of construction sites. The aspects analyzed were Temporary Facilities, Safety, Material Handling and Storage at construction sites by using a checklist developed by Saurin and Formoso (2006). Forty construction sites in the Metropolitan Region of Fortaleza (MRF), Brazil, were analyzed. The results pointed to a direct relationship between the implementation of Lean Construction and LEED Certification and the overall quality of work at construction sites. The concepts of Lean Construction are linked to a better quality of material handling and storage, temporary facilities and safety at construction sites. Also, the LEED Certification influences to a better quality of material handling and storage. Those two aspects combined make the construction site safer and more efficient, reduce material waste and cost, as well as increase the quality of the services executed.
\end{abstract}

Keywords: Lean Construction. LEED Certification. Construction Sites. Construction Quality. Construction Safety.

\section{INTRODUCTION}

The layout planning of a construction site involves identification, dimensioning and adequate allocation of the temporary facilities (Abotaleb et al 2016). This planning is considered to be a highly difficult problem given its complexity (Lien and Cheng 2012). A construction site with a high-quality planning directly affects the construction processes: it diminishes worker's travel time, promotes safety and improves the handling of materials and equipment. That, in turn, increases efficiency and reduces cost, especially for large constructions (Hamiani and Popescu 1988; Tommelein et al 1992).

According to Koskela and Dave (2008), the Lean approach is a new way of analyzing the waste in the production system as well as reducing, or eliminating this waste for better efficiency. The LC aim is to reduce the waste and the cycle time, improve the efficiency, and maximize the value for the client (Ballard et al 2012). These objectives contribute for a good-quality and well-planned construction site by analyzing the similarities between the objectives of LC and the benefits of a high quality site. In this same scenario, the LEED Certification can be an alternative with the same influence on

1 Civil Engineer, M. Sc. Student, Department of Structural Engineering and Civil Construction, Federal University of Ceara, Brazil, thaisdemelo11@gmail.com

2 Professor, Department of Architecture and Urbanism, Federal University of Ceara, Brazil, mariana@dau.ufc.br 
the site. That is possible because, according to the Green Building Council Brasil, the LEED Certification focuses on sustainability and environment preservation.

Therefore, it is hypothesized that there is a direct relationship between LC and LEED Certification, and the quality of the construction site. So, this paper objective is to verify this relationship between LC and the LEED Certification, and the quality of construction sites. For that, an analysis was made using the same criteria for different construction sites in the Metropolitan Region of Fortaleza (MRF), Brazil.

\section{THEORETICAL BASIS}

\subsection{Construction Sites}

Ning et al (2011) affirm the construction sites layout planning was recognized as a critical stage on the construction planning. This is a decisive process that addresses problem and opportunity identification, solution development and the choice and implementation of the best alternatives.

To Serra and Oliveira (2003), a logistic approach must be considered during all the development of the production cycle of the project, i.e., from its conception to the execution phase.

A construction site with a good quality planning allows for a reduction in travel time, minimizes unnecessary material transportation, and significantly impacts the economy, safety as well as other aspects of the construction (Mawdesley et al 2002).

\subsection{LEED Certification and Lean Construction in Construction Sites}

A sustainable building or green construction focus on increasing natural resources efficiency through constructive measures and procedures aiming at reducing construction impacts, without negatively affecting people's health or the environment, while saving money (Krygiel and Nies 2008).

The LEED Certification emerges from considering this sustainable concept. The latest Guide Reference (LEED) (2009) has incorporated more instruments regarding the necessities with care at construction sites.

The LEED certification has sustainability and the preservation of the environment as its main objectives (Green Building Council Brasil). Analyzing these objectives, the certification might have a big influence on the logistics in construction sites, especially in material handling and storage, enabling the correct arrangement of material resulting in loss reduction, as well as the correct collection and destination of these materials by using the most adequate paths. Therefore, LC is one of the philosophies that can contribute to the proper fulfilment of the prerequisites of the LEED Certification.

Womack and Jones (2004) argue that LC is so called because it reduces the quantities when compared with mass production. Therefore, it leads to a reduction in workers' effort, production space, equipment investment, planning time to develop new products, production places inventory and final product delivery problems. Accordingly, $\mathrm{Wu}$ and Wang (2016) argue that this LC philosophy is related to activities that add value to the product or process, and to the reduction of time consumption, expenses and resources.

Considering all aforesaid, LC can have a direct influence on material handling, since it generates a reduction in waste and costs and an increase in productivity. It can also influence on the quality of temporary facilities to better serve the production, adding value to the process and the client. Lastly, it can have an influence on safety at the 
construction site, avoiding extra costs caused by workplace accidents, resulting in a safer and more efficient, in addition to affecting directly the clients' satisfaction.

\subsection{Quality Prerequisites for Construction Sites}

Good planning is necessary for a construction site to have high quality standards. That is especially true regarding temporary facilities, storage, construction safety and material handling. Analyzing the "Norma Regulamentadora 18 (NR 18)" (Regulatory Norm 18) and the work developed by Saurin and Formoso (2006), some requisites are established for each of the items contained in the three main categories, as shown below:

- Temporary facilities: typologies, hoardings and galleries, entries, office on site, sanitary facilities, locker rooms, warehouse, accommodation, eating area, kitchen; laundry and recreation area;

- Safety at construction sites: stairs, ladders, ramps and walkways, safety measures against falls from height, electrical installations, personal protective equipment (PPE), site safety signage, fire protection, crane and scaffolding;

- Handling and storage of materials: handling and storage of materials and personnel (elevator towers, material elevators, elevator for people), material storage and stocking, areas of circulations, tidiness and cleanliness.

In 2006 Saurin and Formoso developed a checklist to analyze 40 construction sites in Rio Grande do Sul, Brazil. This checklist divided the site into the three categories presented previously (Temporary Facilities, Safety at Construction Sites, and Material Handling and Storage). These categories are divided into items, and these into elements, totalizing 128 elements in the complete checklist. The options for checking are "Yes", "No" or "Not applicable".

After answering all 128 elements, a grade is given to evaluate the performance of each of the three categories analyzed according to Equations 1, 2 and 3 below:

$$
\begin{gathered}
\mathrm{IIP}=\frac{P O}{P P} \times 10 \\
\mathrm{IS}=\frac{P O}{P P} \times 10 \\
\mathrm{IMAM}=\frac{P O}{P P} \times 10
\end{gathered}
$$

Where:

IIP is the index of performance concerning Temporary Facilities;

IS is the index of performance concerning Safety at Construction Sites;

IMAM is the index of performance concerning Material Handling and Storage;

PO are the points obtained, i.e., all the elements marked "Yes" for each of the items, worth one point per "Yes";

PP are the obtainable points, i.e., all elements marked as either "Yes" or "No", excluding those marked as "Not Applicable", worth one point every "Yes" or "No".

Then the overall grade is calculated for the Construction Site, also known as "Indice de Boas Práticas de Canteiros de Obras (IBPC)" (Good Practices at Construction Sites Index) for each construction, according to equation 4 below:

$$
\mathrm{IBPC}=\frac{\mathrm{IIP}+\mathrm{IS}+\mathrm{IMAM}}{3} \#(4)
$$


It is important to highlight that these grades vary from 0 to 10 , where 10 is the grade for best performance.

\section{METHOdOLOGY}

In order to verify the influence of LC and LEED Certification on the quality of construction sites, 40 sites from the MRF from 19 different companies were analyzed. Vertical and horizontal constructions in different phases (foundation/excavation, structure/masonry or wall covering/finishing) were observed.

For this analysis a checklist developed by Saurin and Formoso (2006) was used for each of the construction sites. With all the information recorded, grades were given for each of the three main categories: Temporary Facilities, Safety at Construction Sites, and Material Handling and Storage for each site following equations 1, 2 and 3. After that, following equation 4 , the overall grade was calculated for each of these sites.

With all grades in hand, a comparative analysis was made regarding the performance of these sites related to the LEED certification and to the presence of LC. Four graphs were generated with the overall grades and the grades of the items that belonged to the three main categories analyzed.

The division was made into 3 levels: level 1 sites, the ones whose their companies have LEED certification and LC; Level 2 sites, the ones with LC only; and sites with none of the two elements being considered.

We analyzed 8 sites level 1, 10 sites level 2, and 22 sites with none of the two elements. Furthermore, pictures were taken to keep a record of each item analyzed in all construction sites for a better understanding of the real situation analyzed and discussed along this paper.

\section{REsUlTS AND DisCUSSION}

Next, the results and graphs regarding the overall grades and the grades for Temporary Facilities, Safety at Construction Sites and Material Handling and Storage will be discussed.

Analyzing Graph 1, it is seen that level 1 sites present the best results overall, except for Temporary Facilities category, with a difference of only .06 points in relation to level 2 sites, result that will be analyzed in detail in item 4.1.

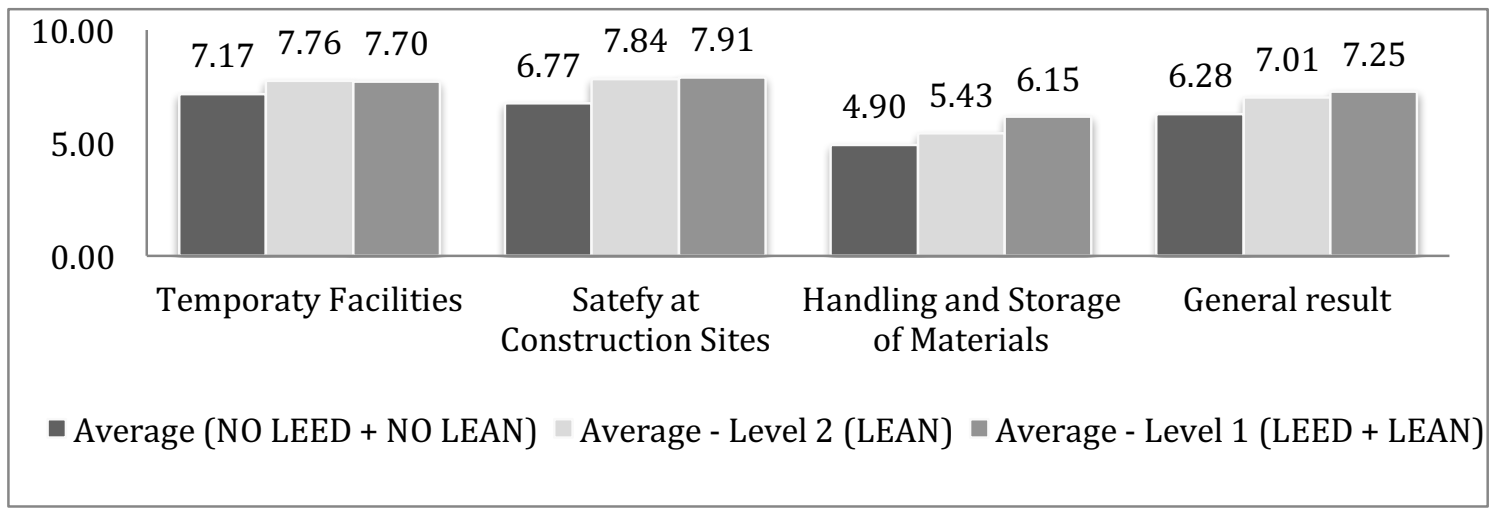

Graph 1: General results for construction sites analysed regarding the LEED certification and Lean Construction 
It was concluded that both LEED certification and LC influence to a better performance at construction sites. The former, regarding the environment and sustainability, relates to the improvement of material storage logistics, whereas the latter, by seeking a reduction of waste and costs and improvement of productivity, influences directly on material arrangement and transport, temporary facilities quality for better serving the productive process and, lastly, construction sites safety, as a protection to human resources avoiding extra costs due to worksite accidents. This, in turn, results in a more efficient production and increases workers' safety, as well as directly influences clients' satisfaction.

It is important to highlight that applying LC principles and obtaining and maintaining the LEED certification require a series of internal and external audits. Which, in turn, influence on meeting the checklist pre-requisites, that are similar to the ones from the Norms and certifications. Next, a detailed analysis will be made of the three categories from the used form.

\subsection{Temporary Facilities}

Graph 2 shows the results regarding Temporary Facilities of construction sites.

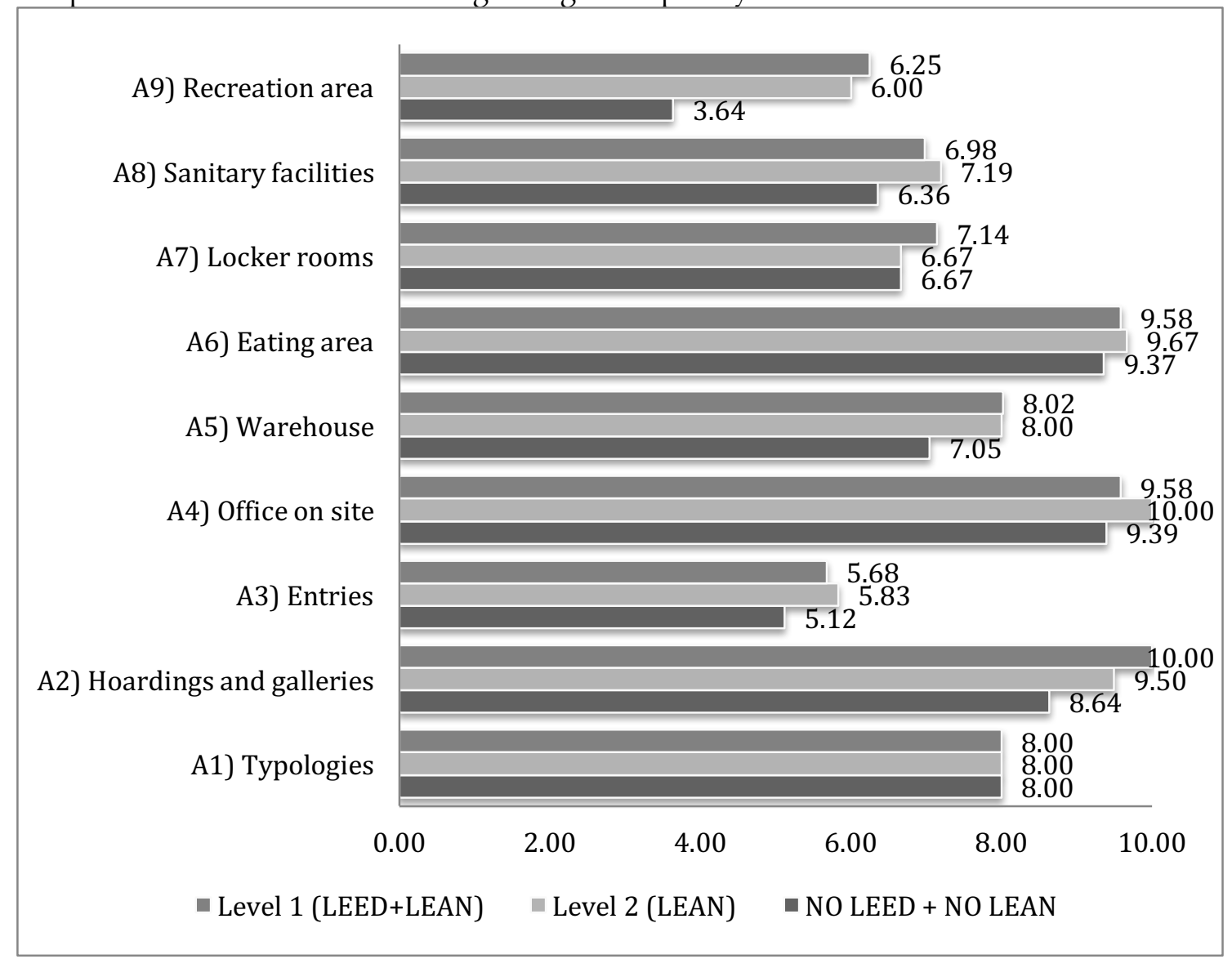

Graph 2: Results regarding temporary facilities

The item regarding worksite entries was not highly graded in none of the levels, whereas the item regarding eating area and offices received the highest grades in all categories. It is verified that levels 1 and 2 constructions show better results. That shows the real influence of LC on temporary facilities, since aiming at better serving the productive process allows greater results in this category. 
Concerning temporary facilities, it is important to observe that level 1 sites showed better results in some aspects, whereas level 2 sites showed superior results in others. This leads to the conclusion that the LEED certification does not influence significantly on the quality of temporary facilities, as expected. This is so due to the fact that this certification has, as its main topics, the environment and sustainability, having bigger influence on items referring to material storage and transportation.

\subsection{Safety at Construction Sites}

Graph 3 shows the results related to the items from Safety at Construction Sites.

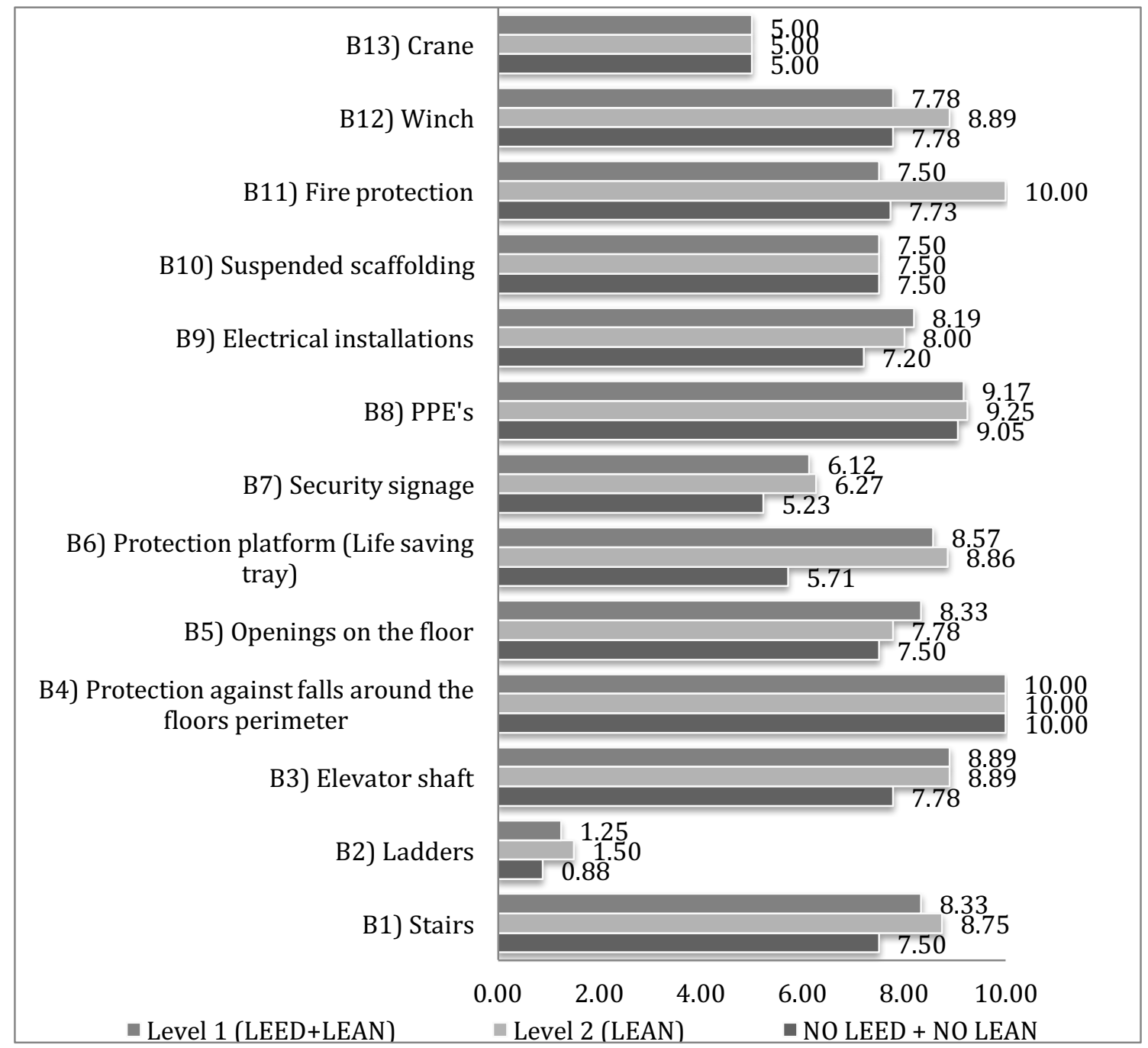

Graph 3: Results related to Safety at Construction Sites

The lowest grade for all levels was given to the ladder item. On the other hand, the highest graded item was related to PPE's and fall protection around the floor perimeter. As expected, level 1 and 2 sites presented higher grades than those without the LEED certification and LC. However, in some categories, level 2 constructions presented higher grades than level 1 constructions. That can be explained the same way that it could for Temporary Facilities: as a consequence of the LEED certification being more focused on the environment and sustainability, it does not influence, in a significant way, on construction sites safety for not addressing it. 
Despite of that, it is relevant to point out the LC influence on safety, hence protecting workers from potential accidents and the generation of additional costs making the production more efficient and influencing the clients' satisfaction.

\subsection{Material Handling and Storage}

Graph 4 shows the results related to Material Handling and Storage.

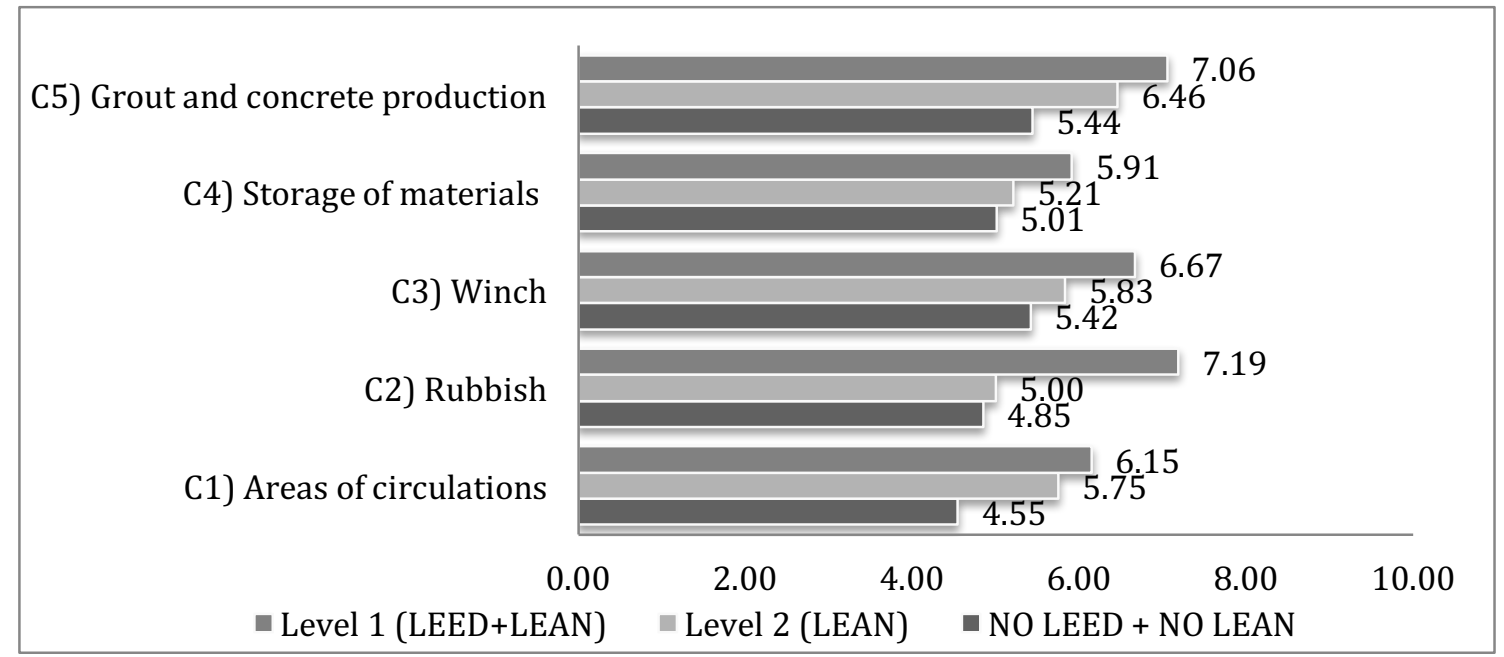

Graph 4: Results related to Material Handling and Storage

Overall, the grades for this category were very low in all the items. However, all grades for this category were superior for level 1 sites, unlike the temporary facilities and safety at construction sites.

Therefore, the obtained numbers prove the LEED certification significantly influences on material handling and storage. By having requisites regarding the preservation of the environment and sustainability, the certification ends up demanding the adequate material storage and better transport logistics, which are precisely the points required in this category.

The direct influence of LC is also verified in this category since by aiming at reducing waste and costs and increasing productivity, it directly influences material arrangement and transport.

\section{CONCLUSION}

Analyzing the results of this study, it was possible to conclude that LC has a direct influence on Temporary Facilities, Safety at Construction Sites and on Material Handling and Storage. Moreover, the LEED certification has a more direct influence on material handling and storage. That way, it is possible to affirm that LC and LEED certification have a direct impact on the quality of construction sites.

In order to improve this research, the authors suggest adding some elements to the checklist that are very important and were not approached in this analysis, such as industrialized mortar control and storage of ceramics, paints, countertops and other finishing items. Moreover, the options of filling the checklist with fractioned grades from 0 to 1 , instead of with "yes", "no" and "not applicable", makes the evaluation fairer for when a specific element presents itself partially in accordance with the demand. That change would make it possible for a better and fairer evaluation of the situation in each 
construction site. It would also be interesting to undertake a more representative study, with more than 40 construction sites in different states or countries.

\section{REFERENCES}

Abotaleb, I., Nassar, K., and Hosny, O. (2016). Layout optimization of construction site facilities with dynamic freeform geometric representations. Automation in Construction, 66, pp. 15-28.

Ballard, G., Picchi, F., Sacks, R. (2012). Production System Design. International Group for Lean Construction, 10 October, 2012.

Hamiani, A., and Popescu G. (1988). CONSITE: A knowledge-based expert system for site layout Computing in Civil Engineering. Proceeding of the 5th Conference on Computing in Civil Engineering: Microcomputers to Supercomputers, ASCE, Alexandria, Virginia, pp. 248-256.

Green Building Council Brasil. Available at: <http://gbcbrasil.org.br/sobrecertificado.php> [Accessed 15 April 2016].

Leed. Guide Reference (version 3.0). (2009).

Krygiel, E., and Nies, B. (2008). Green Bim. Successful Sustainable: Design with Building Information Modeling. Indianapolis. In: Wiley Publishing.

Koskela, L., and Dave, B. (2008). Process and IT. Construction Innovation: Information, Process, Management, 8(4), pp. 244-249. ISSN 1471-4175.

Lien, L.C., and Cheng, M.Y. (2012). A hybrid swarm intelligence based particle-bee algorithm for construction site layout optimization. Expert Systems with Applications, 39(10), pp. 9642-9650.

Mawdesley, M.J., Al-Jibouri, S.H., and Yang, H. (2002). Genetic algorithms for construction site layout in project planning. ASCE Journal of construction engineering and management, 128(5), pp. 418-426, doi: 10.1061/ (ASCE)07339364(2002)128:5(418), 418-426.

Norma Regulamentadora - 18 - Condições e Meio Ambiente de Trabalho na Indústria da Construção. Available at: $<$ http://www.guiatrabalhista.com.br/legislacao/nr/nr4.htm>[Accessed 29 March 2016]. Ning, X., Lamb, K.C., and Lam, M.C.K. (2011). A decision-making system for construction site layout planning. Automation in Construction, 20(4), pp. 459-473.

Saurin, T.A., and Formoso, C.T. (2006). Planejamento de Canteiros de Obra e Gestão de Processos. Recomendações Técnicas HABITARE, Volume 3, Porto Alegre, Brasil.

Serra, S. M. B., and Oliveira, O.J. (2003). Development of the Logistics Plan in Building Construction. In: Bontempi (ed.) System-based Vision for Strategic and Creative Design, pp. 75-80. Lisse, Swets\&Zeitlinger.

Tommelein, I.D., Levit, R.E., and Hayes-Roth, B. (1992). Site Plan model for site layout. $A S C E$ Journal of Construction Engineering and Management, 118 (4), pp. 749-766.

Womack, J. P., and Jones, D. T. (2004). A máquina que mudou o mundo. Gulf Professional Publishing.

Wu, P., and Wang, X. (2016). A Critical Review of the Factors Affecting the Success of Using Lean to Achieve Green Benefits. International Group for Lean Construction, 20-22 July, 2016. 